\title{
Green and Efficient Synthesis and Characterization of Amino Chromene Derivatives with Add Alkyl Tail
}

\author{
Madasamy Kumar, Veerappan Jeyachandran, ArumugamSathamraja, PandianPaulraj
}

\begin{abstract}
The reaction between substituted 4-hydroxybenzaldehyde, active methylene compounds and /or resorcinol yield aminochromene derivatives. Structures of these compounds were established upon the basis of IR,1HNMR,13CNMR, and MASSdata.
\end{abstract}

Keywords: chromenes, imines, amines, antioxidants

\section{INTRODUCTION}

Multicomponent reactions (MCRS) are reactions where numerous reactants involved in single synthetic operation and give new compounds. 1 This type of reactions avoids purification process and often wide variety of complex molecule in a single step, inturn it is very useful for saving solvent and reagents. Among many heterocyclic compounds, chromenes are very important due to its biological activity such as antioxidants, 2 anticancer,anti-microbial, 3 anti-inflammatory, 4 anti-HIV,5 and anti-tumor, 6 alzimer disease, 7 antihypotensive 8 and antileishmanial. 9 There are many reports shown that synthesis of different chromene derivatives and its applications (Figure 1).1, 10, 11 A Knoevenagel condensation is the reaction between salicylaldehyde with active methylene compounds followed by intramolecular cyclisation to give imino derivatives 11 . As per reports, different products are obtained by control of a solvent, 12 ratio of reagents and temperature13etc., Due to importance of these chromene derivatives, numerous green approaches 14 have been developed under distinct conditions like thermal heating, 15 microwave, 16 ultrasonic, 17 electrochemical, infrared, and solvent free conditions. We could not find many reports on variation of an alkyl side chain to see the effect on antioxidant properties of chromene derivatives. So we are motivated to synthesis aminochromenes by taking alkylated aldehyde and malonitrile. Currently, many investigations are going on.18, 19,20

Revised Manuscript Received on December 11, 2019

Madasamy Kumar, Department Of Science \& Humanities, Bharath Institute Of Higher Education And Research TamilNadu,India.Email: kmrorg@gmail.com

VeerappanJeyachandranDepartment Of Science \& Humanities, Bharath Institute Of Higher Education And Research TamilNadu,IndiaEmail: jeyorg@gmail.com

Arumugam Sathamraja Department Of Science \& Humanities, Bharath Institute Of Higher Education And Research TamilNadu,India.Email: sathamrajaarumugam@gmail.com

PandianPaulraj Department Of Science \& Humanities, Bharath Institute Of Higher Education And Research TamilNadu,India.Email: paulrajp.che@bharathuniv.ac.in<smiles>[R][NH2+]C([Y9])([Y9])C1C([Y])=C(N)Oc2ccccc21</smiles><smiles>[R]NC(=O)c1cc2cccc(OC)c2oc1=O</smiles>

Figure 1. Examples for different chromene derivatives

\section{EXPERIMENTAL METHOD AND TECHNIQUES}

All NMR spectra were recorded using Bruker $(300 \mathrm{MHz})$ spectrometer. JASCO-FTIR spectrometer $\left(4000-400 \mathrm{~cm}^{-1}\right)$ used for recording Infrared spectra. Electro spray ionization mass spectrometry (ESI-MS) analysis was performed in the negative ion mode on a liquid chromatography-ion trap mass spectrometer (LCQ Fleet, Thermo Fisher Instruments Limited,US).The DPPH radical scavenging action of the compounds was dignified rendering to the method of Blios. ${ }^{20}$ The assay of nitric oxide (NO), $\mathrm{H}_{2} \mathrm{O}_{2},\left(\mathrm{O}_{2}^{-}\right)$scavenging activity was determined using the method available in literature. $^{22,27,28}$

Aseriesof2-amino-7-hydroxy-4-(4-(alkyloxy)

phenyl)- $4 H$-chromene-3-carbonitrile havebeensynthesized using calcium hydroxide as efficient and green catalyst. Thestructureswereconfirmedby ${ }^{1} \mathrm{H}-\mathrm{NMR},{ }^{13} \mathrm{C}-\mathrm{NMR}$, FT-IRandmassspectroscopictechniques.

\section{RESULTS \& DISCUSSION}

\section{A. General procedure for the synthesis Of} 4-alkoxybenzaldehyde: 2a-h

A mixture of 4-hydroxybenzaldehyde (10mmol,1eq) 1-bromoalkane (15mmol,1.5eq),

anhydrous $\mathrm{K}_{2} \mathrm{CO}_{3}(15 \mathrm{mmol}, 1.5 \mathrm{eq})$ and butanone $20 \mathrm{ml}$, the catalytic amount of KI was added to the mixture was refluxed for 4hours. Reaction mixture was concentrated, poured into water and extracted with dichloromethane(DCM)(20mlx2). The combined organic clayer was washed with brine and over anhydrous $\mathrm{Na}_{2} \mathrm{SO}_{4}$. Evaporation of solvent furnished a brown colored mass which was purified by column chromatography on 60-120 mesh silicagel. Elution with a mixture of 
ethylacetate-petether(1:9)furnished the pure light yellow oilyliquid. $^{29}$

\section{B. General procedure for the preparation of 4-alkoxybenzoicacid: 3a-h}

The4-alkoxybenzaldehyde(1g)wasdissolvedinbutanone(20m 1)and jones reagent $\left(1.7 \mathrm{gCrO}_{3}, 2 \mathrm{mlH}_{2} \mathrm{SO}_{4}\right.$ and $\left.6 \mathrm{mlH}_{2} \mathrm{O}\right)$ was slowly added to this mixture andstirredfor 1hour.After1hour,tothismixturewaterwas added

slowly.Thewhiteprecipitatewasfiltered;itwaswashedwithwat erandrecrystallizedbyethanolgivepureproduct. ${ }^{30}$

\section{General procedure for the preparation of 4-formyl-3-hydroxyphenyl-4-(alkoxy)benzoate: 4a-h}

A stirred solution of 4-alkoxybenzoicacid(1eq), 2,4-dihydroxybenzaldehyde (1.1eq),N,N-Dicyclo hexylcarbodiimide(DCC)(3eq) and catalytic amount of (DMAP) dimethy laminopyridinein (DCM) dichloromethane solution was added at the room temperature, mixture was vacuum created and stirred for overnight under $\mathrm{N}_{2}$ atmosphere. The precipitate $\mathrm{N}, \mathrm{N}$-dicyclohexylure a was filtered off. The filtrate was diluted with (20ml) DCM and washed with water and dried over anhydrous $\mathrm{Na}_{2} \mathrm{SO}_{4}$. Evaporate solvent by vacuum pump and purified by column chromatography60-120 meshsilicagel.Elution with a mixture of (1:9)ethylacetate-pet ether furnished the pure a product.The product was recrystallized from $\mathrm{CH}_{2} \mathrm{Cl}_{2}$-acetonitrile too obtain a white solid. ${ }^{24}$

\section{2-amino-7-hydroxy-4-(4-(alkoxy)phenyl)-4H-chrome ne-3-carbonitrile:5a-h}

A

mixture

of

resorcinol(1.0mmol),2-(4-methoxybenzylidene),

malononitrile $(1.5 \mathrm{mmol})$, and $\mathrm{Ca}(\mathrm{OH})_{2}(1.0 \mathrm{mmol})$ in $5 \mathrm{~mL}$ of methanol was stirred at room temperature for $5 \mathrm{~min}$. After completion of there action monitored by TLC, the crude was washed with ethylacetate, dissolved with THF and filter to separate the catalyst. Solvent was removed from filtrate gave the pure product.

\section{CONCLUSIONS}

Spinel $\mathrm{ZnAl}_{2} \mathrm{O}_{4}$ sample was synthesized successfully by a facile microwave heating route using $H$. rosa-sinensis extract. XRD, EDX and FT-IR results specified that the prepared spinel $\mathrm{ZnAl}_{2} \mathrm{O}_{4}$ sample have spinel structure with well crystalline product and also free from other phase impurities. The HR-SEM result revealed that spinel $\mathrm{ZnAl}_{2} \mathrm{O}_{4}$ sample contain nanoparticle-like morphology. The specific $\mathrm{M}_{\mathrm{s}}$ values were obtained to be $0.023 \mathrm{emu} / \mathrm{g}$ for spinel $\mathrm{ZnAl}_{2} \mathrm{O}_{4}$ sample.

\section{REFERENCES}

1. A. Manikandan, M. Durka, K. Seevakan, S. Arul Antony, A novel one-pot combustion synthesis and opto-magnetic properties of magnetically separable spinel $\mathrm{Mn}_{x} \mathrm{Mg}_{1-x} \mathrm{Fe}_{2} \mathrm{O}_{4} \quad(0.0 \leq x \leq 0.5)$ nano-photocatalysts, Journal of Superconductivity and Novel Magnetism, 28 (2015) 1405-1416.

2. A. Manikandan, M. Durka, S. Arul Antony, One-pot flash combustion synthesis, structural, morphological and opto-magnetic properties of spinel $\mathrm{Mn}_{x} \mathrm{Co}_{1-x} \mathrm{Al}_{2} \mathrm{O}_{4}$ ( $x=0,0.3$ and 0.5$)$ nano-catalysts, Journal of Superconductivity and Novel Magnetism, 28 (2015) 209-218.

3. A. Manikandan, M. Durka, S. Arul Antony, Hibiscus rosa-sinensis leaf extracted green methods, magneto-optical and catalytic properties of spinel $\mathrm{CuFe}_{2} \mathrm{O}_{4}$ nano- and microstructures, Journal of Inorganic and Organometallic Polymers and Materials, 25 (2015) 1019-1031.

4. A. Manikandan, M. Durka, S. Arul Antony, A novel synthesis, structural, morphological and opto-magnetic characterizations of magnetically $\quad$ separable $\quad$ spinel $\mathrm{Co}_{\mathrm{x}} \mathrm{Mn}_{1-\mathrm{x}} \mathrm{Fe}_{2} \mathrm{O}_{4}$ $(0 \leq \mathrm{x} \leq 1)$ nano-catalysts, Journal of Superconductivity and Novel Magnetism, 27 (2014) 2841-2857.

5. A. Manikandan, S. Arul Antony, R. Sridhar, M. Bououdina, A simple combustion synthesis and optical studies of magnetic $\mathrm{Zn}_{1-x} \mathrm{Ni}_{x} \mathrm{Fe}_{2} \mathrm{O}_{4}$ nanostructures for photoelectrochemical applications, Journal of Nanoscience and Nanotechnology, 15 (2015) 4948-4960.

6. A. Manikandan, M. Durka, S. Arul Antony, Magnetically recyclable spinel

$\mathrm{Mn}_{\mathrm{x}} \mathrm{Zn}_{1-\mathrm{x}} \mathrm{Fe}_{2} \mathrm{O}_{4} ;(0.0 \leq \mathrm{x} \leq 0.5)$ nano-photocatalysts, Advanced Science, Engineering and Medicine, 7 (2015) 33-46.

7. A. Manikandan, E. Hema, M. Durka, K. Seevakan, T. Alagesan, S. Arul Antony, Room temperature ferromagnetism of magnetically recyclable photocatalyst of $\mathrm{Cu}_{1-\mathrm{x}} \mathrm{Mn}_{\mathrm{x}} \mathrm{Fe}_{2} \mathrm{O}_{4}-\mathrm{TiO}_{2}(0.0 \leq \mathrm{x} \leq 0.5)$ nano-composites, Journal of Superconductivity and Novel Magnetism, 28 (2015) 1783-1795.

8. A. Manikandan, M. Durka, S. Arul Antony, Role of $\mathrm{Mn}^{2+}$ doping on structural, morphological and opto-magnetic properties of spinel $\mathrm{Mn}_{\mathrm{x}} \mathrm{Co}_{1-\mathrm{x}} \mathrm{Fe}_{2} \mathrm{O}_{4}(x=0.0,0.1,0.2,0.3,0.4$ and 0.5$)$ nano-catalysts, Journal of Superconductivity and Novel Magnetism, 28 (2015) 2047-2058.

9. K. Chinnaraj, A. Manikandan, P. Ramu, S. Arul Antony, P. Neeraja, Comparative study of microwave and sol-gel assisted combustion methods of $\mathrm{Fe}_{3} \mathrm{O}_{4}$ nanostructures: Structural, morphological, optical, magnetic and catalytic properties, Journal of Superconductivity and Novel Magnetism, 28 (2015) 179-190.

10. M. F. Valan, A. Manikandan, S. Arul Antony, Microwave combustion synthesis and characterization studies of magnetic $\mathrm{Zn}_{1-x} \mathrm{Cd}_{x} \mathrm{Fe}_{2} \mathrm{O}_{4}(0 \leq x$ $\leq 0.5$ ) nanoparticles, Journal of Nanoscience and Nanotechnology, 15 (2015) 4543-4551.

11. E. Hema, A. Manikandan, S. Suganya, M. Durka, S. Arul Antony, B. R. Venkatraman, A novel synthesis of $\mathrm{Zn}^{2+}$-doped $\mathrm{CoFe}_{2} \mathrm{O}_{4}$ spinel nanoparticles: Structural, morphological, opto-magnetic and catalytic properties, Journal of Superconductivity and Novel Magnetism, 28, 8 (2015) 2539-2552

12. P. Paulraj, N. Janaki, S. Sandhya, K. Pandian, Single pot synthesis of polyaniline protected silver nanoparticles by interfacial polymerization and study its application on electrochemical oxidation of hydrazine, Colloids and Surfaces A: Physicochem. Eng. Aspects 377 (2011) 28-34.

13. S. Jayasree, A. Manikandan, A. M. Uduman Mohideen, C. Barathiraja, E. Hema, S. Arul Antony, Comparative study of combustion methods, opto-magnetic and catalytic properties of spinel $\mathrm{CoAl}_{2} \mathrm{O}_{4}$ nano- and microstructures, Advanced Science, Engineering and Medicine, 7, (2015) 672-682.

14. A. Mary Jacintha, A. Manikandan, K. Chinnaraj, S. Arul Antony, P. Neeraja, Comparative studies of spinel $\mathrm{MnFe}_{2} \mathrm{O}_{4}$ nanostructures: Structural, morphological, optical, magnetic and catalytic properties, Journal of Nanoscience and Nanotechnology, 15, 9732-9740 (2015)

15. R. Marx Nirmal, P. Paulraj, K. Pandian, K. Sivakumar, Preparation, Characterization and Photocatalytic Properties of CdS and Cd1-xZnxS nanostructures, AIP Conf. Proc. 1391 (2011) 597-599.

16. A. Manikandan, M. Durka, M. Autha Selvi, S. Arul Antony, Sesamum indicum plant extracted microwave combustion synthesis and opto-magnetic properties of spinel $\mathrm{Mn}_{\mathrm{x}} \mathrm{Co}_{1-\mathrm{x}} \mathrm{Al}_{2} \mathrm{O}_{4}$ nano-catalysts, Journal of Nanoscience and Nanotechnology, 16 (2016) 448-456

17. E. Prabakaran, S. Parani, M. Alexander, P. Paulraj, K. Pandian, Synthesis of chitosan oligomer stabilized silver nanorod and its modified glassy carbon electrode for reduction of chlorophenols, J. Nanosci. Lett. 3 (2013) 18(1-9)

18. A. Manikandan, R. Sridhar, S. Arul Antony, S. Ramakrishna, A simple aloe vera plant-extracted microwave and conventional combustion synthesis: Morphological, optical and catalytic properties of magnetic $\mathrm{CoFe}_{2} \mathrm{O}_{4}$ nanostructures, Journal of Molecular Structure, 1076 (2014) 188-200.

19. K. Kaviyarasu, E. Manikandan, P. Paulraj, S.B. Mohamed, J. Kennedy, One dimensional well-aligned $\mathrm{CdO}$ nanocrystal by solvothermal method, Journal of Alloys and Compounds 593 (2014) 67-70.

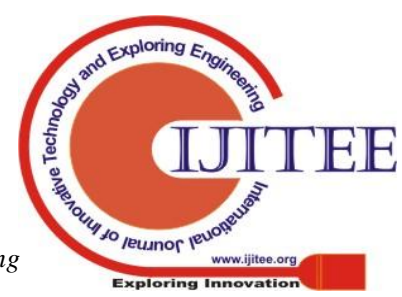


20. A. Manikandan, M. Durka, M. Amuth Selvi, S. Arul Antony, Aloe vera plant extracted green synthesis, structural and opto-magnetic characterizations of spinel $\mathrm{Co}_{\mathrm{x}} \mathrm{Zn}_{1-x} \mathrm{Al}_{2} \mathrm{O}_{4}$ nano-catalysts, Journal of Nanoscience and Nanotechnology, 16 (2016) 357-373

21. P. Paulraj, A. Manikandan, E. Manikandan, K. Pandian, M. K. Moodley, K. Roro, and K. Murugan, Solid-State Synthesis of POPD@AgNPs Nanocomposites for Electrochemical Sensors, J. Nanosci. Nanotechnol. 18 (2018) 3991-3999.

22. P. Bhavani, A. Manikandan, P. Paulraj, A. Dinesh, M. Durka, S. Arul Antony, Okra (Abelmoschus esculentus) Plant Extract-Assisted Combustion Synthesis and Characterization Studies of Spinel $\mathrm{ZnAl}_{2} \mathrm{O}_{4}$ Nano-Catalysts, J. Nanosci. Nanotechnol. 18 (2018) 4072-4081.

\section{AUTHORS PROFILE}

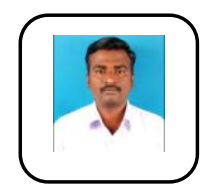

Madasamy Kumar, Associate Professor Departmen Of Science \& Humanities, Bharath Institute Of Higher Education And Research TamilNadu,India

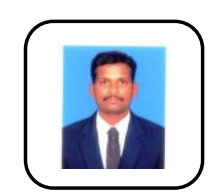

Veerappan Jeyachandran,, Associate Professor Department Of Science \& Humanities, Bharath Institute Of Higher Education And Research TamilNadu,India

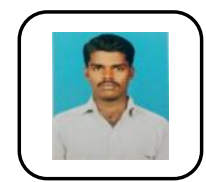

Arumugam Sathamraja Lab Instructor Department Of Science \& Humanities, Bharath Institute Of Higher Education And Research TamilNadu,India

Pandian Paulraj, Associate Professor, Department Of Science \& Humanities, Bharath Institute Of Higher Education And Research TamilNadu,India 